\title{
BMJ Open Malnutrition assessment methods in adult patients with tuberculosis: a systematic review
}

\author{
Lies ter Beek (1) , ,2,3 Mathieu S Bolhuis, ${ }^{4}$ Harriët Jager-Wittenaar, ${ }^{5,6}$ \\ René X D Brijan, ${ }^{3}$ Marieke G G Sturkenboom, ${ }^{4}$ Huib A M Kerstjens, ${ }^{1}$ \\ Wiel C M de Lange, ${ }^{1,2}$ Simon Tiberi, ${ }^{7,8}$ Tjip S van der Werf (D) , 1,9 \\ Jan-Willem C Alffenaar, ${ }^{10,11,12}$ Onno W Akkerman (1) ${ }^{1,2}$
}

To cite: ter Beek L, Bolhuis MS, Jager-Wittenaar $\mathrm{H}$, et al. Malnutrition assessment methods in adult patients with tuberculosis: a systematic review. BMJ Open 2021;11:e049777. doi:10.1136/ bmjopen-2021-049777

- Prepublication history and additional supplemental material for this paper are available online. To view these files, please visit the journal online (http://dx.doi.org/10.1136/ bmjopen-2021-049777)

LtB and MSB contributed equally.

Received 04 February 2021 Accepted 19 November 2021
Check for updates

(C) Author(s) (or their employer(s)) 2021. Re-use permitted under CC BY-NC. No commercial re-use. See rights and permissions. Published by BMJ.

For numbered affiliations see end of article.

Correspondence to Dr Onno W Akkerman; o.w.akkerman@umcg.nl

\section{ABSTRACT}

Objectives Malnutrition is associated with a twofold higher risk of dying in patients with tuberculosis (TB) and considered an important potentially reversible risk factor for failure of TB treatment. The construct of malnutrition has three domains: intake or uptake of nutrition; body composition and physical and cognitive function. The objectives of this systematic review are to identify malnutrition assessment methods, and to quantify how malnutrition assessment methods capture the international consensus definition for malnutrition, in patients with TB. Design Different assessment methods were identified. We determined the extent of capturing of the three domains of malnutrition, that is, intake or uptake of nutrition, body composition and physical and cognitive function.

Results Seventeen malnutrition assessment methods were identified in 69 included studies. In 53/69 (77\%) of studies, body mass index was used as the only malnutrition assessment method. Three out of 69 studies (4\%) used a method that captured all three domains of malnutrition.

Conclusions Our study focused on published articles. Implementation of new criteria takes time, which may take longer than the period covered by this review. Most patients with TB are assessed for only one aspect of the conceptual definition of malnutrition. The use of international consensus criteria is recommended to establish uniform diagnostics and treatment of malnutrition.

PROSPERO registration number CRD42019122832.

\section{BACKGROUND}

In 2019, tuberculosis (TB) was the worldwide leading cause of death from a single infectious agent, with 10 million new patients, and 1.2 million deaths. ${ }^{1}$ TB prevalence is up to 20 times higher among people living in lowincome countries compared with high-income countries. ${ }^{2} \mathrm{~TB}$, poverty and malnutrition are closely linked. Prevalence of malnutrition in patients with TB is studied to be $50 \%$ to $57 \%$, and malnutrition is associated with a twofold risk of dying. ${ }^{3-9}$
Strengths and limitations of this study

- PubMed, CINAHL and EMBASE were systematically searched for studies in the last decade, to prevent older studies describing outdated supportive care strategies to be eligible for inclusion.

- As there is no instrument for 'risk of bias assessment' of studies on diagnosis (eg, malnutrition assessment), we evaluated risk of bias by scoring the presence of essential components required for adequate assessment and reporting of malnutrition.

- To report on how malnutrition was assessed in studies on tuberculosis (TB), we quantified how malnutrition assessment methods capture the international consensus definition for malnutrition, in patients with TB.

- Implementation of new criteria in study protocols takes time. This implementation might take longer than the time period used in this review.

As hunger-related malnutrition caused by food-insecurity impacts the immune system, ${ }^{1} 1011$ malnutrition is an important risk factor for re-activation of TB, with a reported $27 \%$ attributable risk. ${ }^{12}$ Malnutrition is considered an important, potentially reversible risk factor for treatment failure. ${ }^{13}$ Therefore, a better understanding in assessing malnutrition in patients with $\mathrm{TB}$ is urgently needed. $^{14}$

The European Society for Clinical Nutrition and Metabolism (ESPEN) defines malnutrition as 'a state resulting from lack of intake or uptake of nutrition that leads to altered body composition (decreased fat-free mass) and body cell mass leading to diminished physical and mental function and impaired clinical outcome from disease'. ${ }^{10}$ In patients with TB, two types of malnutrition may coexist: malnutrition without disease ${ }^{10}$; and disease-related malnutrition once active disease has developed. The latter is often driven by a combination of loss of appetite, malabsorption and/ or inflammation-driven catabolism. ${ }^{10}{ }^{11} \mathrm{~A}$ low 
body mass index (BMI) is a characteristic for chronic malnutrition. ${ }^{15}$ However, since malnutrition leads to loss of fat-free mass in all individuals, including those who are overweight or obese, patients with either a normal or high BMI may be malnourished as well. ${ }^{10}$ In 2015, ESPEN published their first consensus on diagnostic criteria for malnutrition, ${ }^{15}$ followed by the Global Leadership Initiative on Malnutrition (GLIM) criteria in 2018, which were established by ESPEN, the American Society for Parenteral and Enteral Nutrition, la Federación Latino Americano de Terapia Nutriconal, Nutricion Clinica y Metabolismo and the Parenteral and Enteral Nutrition Society of Asia. ${ }^{16}$

It was not until 2013 that the WHO presented their first guideline on nutritional care and support for patients with TB. In this guideline, the WHO stressed that all patients with active TB receive individualised nutritional assessment and management, including dietary counselling and nutritional interventions, to improve nutritional status and consequently, prevent TB treatment failure. ${ }^{17}$ Nutritional assessment is a necessary step in the 'nutritional care process', enabling the professional to design a treatment plan together with the patient. ${ }^{18}$ However, the 2013 WHO guideline only refers to BMI as a method of assessing malnutrition for adults. The important issue of lack of consistency and understanding of how malnutrition can be assessed in patients with TB results from, the complexity of TB being on the one hand strongly associated with malnutrition and on the other by the vertical and siloed nature of TB programmes.

The primary aim of this review is to identify malnutrition assessment methods that are used in adult patients with TB. The secondary aim is to quantify how malnutrition assessment methods capture the international consensus definition for malnutrition in this population.

\section{METHODS}

The protocol for this review was registered at PROSPERO with number CRD42019122832. The Preferred Reporting Items for Systematic Reviews and Meta-Analyses (PRISMA) statement was used. ${ }^{19}$

\section{Search strategy}

In September 2020, PubMed, CINAHL and EMBASE were systematically searched for studies in any language. The search term consisted of a domain describing 'malnutrition' and a domain describing 'tuberculosis', while excluding in vitro, animal and paediatric studies. Details of the search strategy can be found in online supplemental material 1.

\section{Inclusion and exclusion criteria}

Studies in the English language that aimed to assess malnutrition and described a method for assessment of malnutrition in patients with microbiologically confirmed or clinically diagnosed TB, published between 1 January 2009 and 18 September 2020 were considered eligible for inclusion. Since the aim of the review is to identify how malnutrition is assessed in current research, 2009 was chosen as a starting point. Restricting the search to the last decade will prevent older studies describing outdated supportive care strategies to be eligible for inclusion.

Only studies that focused on adult patients with TB were included, because the assessment of malnutrition in children requires different methods than in adults as children are growing, and the criteria for measuring their nutritional status differ per by age. ${ }^{20}$

Reviews and study protocols were excluded since they do not present original data. Case reports and abstracts/ posters were also excluded since the information provided on methods used in this type of publication is considered too limited.

\section{Study selection}

Screening of title and abstract was done independently by two authors using the Rayyan web application. ${ }^{21}$ Evaluation of the screening of the first 10 articles was used to define the criteria that determine which studies were eligible for final inclusion. Final inclusion was based on an independent judgement of the full text of both authors. Disagreements about inclusion were resolved through discussion and if consensus was not reached, a third author was consulted, which resulted in consensus in all cases.

\section{Patient and public involvement No patient involved}

\section{Data collection}

Data collection was performed by two authors independently. The following characteristics were extracted from each study: citation, first author, country, years of publication and data collection, aim of the malnutrition assessment, number of included patients, number of HIV coinfected patients, disease location, drug susceptibility of the Mycobacterium tuberculosis isolate.

\section{Data analysis}

To report on how malnutrition was assessed in studies on $\mathrm{TB}$, we determined the extent of capturing of the three domains of malnutrition, malnutrition included in the ESPEN conceptual definition of malnutrition, that is, intake or uptake of nutrition (Domain A), body composition (Domain $\mathrm{B}$ ), and physical and cognitive function (Domain C). ${ }^{1022} 23$

Domain A was considered to be covered to some extent $(+)$ if the method addressed nutritional intake or uptake at all. It was considered to be covered extensively (++) if the method addressed nutritional intake or uptake in depth. For domain B, weight change, BMI and anthropometric measurements, such as skinfold measurements were considered covering domain B to some extent $(+)$. It was considered extensively addressed $(++)$ if the method 
included identification of muscle mass, lean mass or fatfree mass. Domain $\mathrm{C}$ was considered to be covered to some extent $(+)$ if functionality was addressed. Domain C was considered extensively covered $(++)$ if physical (eg, handgrip strength), mental and cognitive function tests were performed, or questions about activities of daily living were addressed.

As micronutrient or trace elements in serum are not representative for intake or uptake of protein or energy, ${ }^{10}$ laboratory tests were not considered to attribute to any of the malnutrition domains. Serum albumin and C reactive protein are parameters for inflammation but are not related to parameters of protein/energy intake or functionality, nor do they represent body composition and were therefore not taken into consideration. In addition, while prealbumin (ie, transthyretin) is sensitive for changes in protein and energy intake, this marker is influenced by inflammation activity. ${ }^{10}$

As there is no instrument for 'risk of bias assessment' of studies on diagnosis (eg, malnutrition assessment), we evaluated risk of bias by scoring the presence of essential components required for adequate assessment and reporting of malnutrition. The risk of bias in included studies was assessed by rating the following four characteristics:

- Rationale for the assessment of malnutrition.

- Malnutrition was assessed and clear cut-off points were described in the method section. For example: 'malnutrition was assessed as BMI $<18.5 \mathrm{~kg} / \mathrm{m}^{2}$.

- Malnutrition was reported in the results section.

- The results with regard to malnutrition were reflected on in the discussion section.

The characteristics were graded for quality of the study. Risk of bias was rated by - (meaning high risk of bias), + (medium risk of bias), or ++ (low risk of bias). The scores were added and the total was translated into very low $(\geq 7$ plusses), low (5-6 plusses), medium (3-4 plusses) or high risk of bias ( $\leq 2$ plusses).

\section{RESULTS}

The search resulted in 2175 studies after removal of duplicates. After screening by title and abstract, 272 studies were selected for a full text eligibility check. Review of the full text resulted in inclusion of 69 studies. ${ }^{34-91}$ A flow diagram of the selection process is visualised in figure 1.
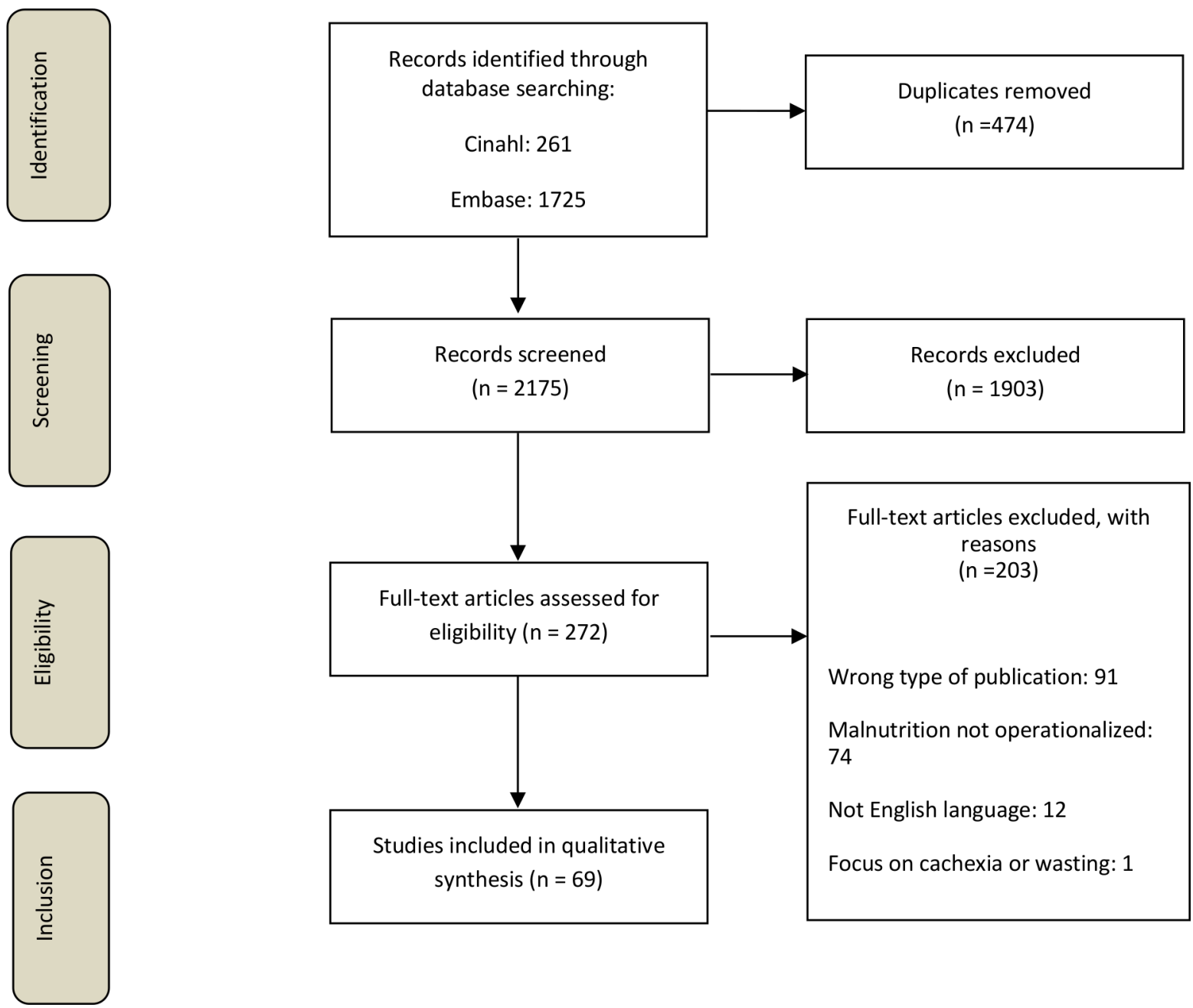

Figure 1 Flow diagram of the selection process of studies describing assessment in the context of malnutrition. 
Table 1 Cut-off values BMI exclusively used

\begin{tabular}{lc}
\hline Cut-off value & $\begin{array}{l}\text { Studies using only BMI for } \\
\text { assessment of malnutrition } \mathbf{n}=53\end{array}$ \\
\hline$\leq 20.0 \mathrm{~kg} / \mathrm{m}^{2}$ & 1 \\
$<20.0 \mathrm{~kg} / \mathrm{m}^{2}$ & 2 \\
$<18.5 \mathrm{~kg} / \mathrm{m}^{2}$ & 34 \\
$\leq 18.5 \mathrm{~kg} / \mathrm{m}^{2}$ & 3 \\
$<18.49 \mathrm{~kg} / \mathrm{m}^{2}$ & 1 \\
$<18.4 \mathrm{~kg} / \mathrm{m}^{2}$ & 1 \\
$<17.0 \mathrm{~kg} / \mathrm{m}^{2}$ & 2 \\
$<16.0 \mathrm{~kg} / \mathrm{m}^{2}$ & 2 \\
No clear cut-off value & 7 \\
described in study & \\
\hline
\end{tabular}

BMI, body mass index.

In total, among 69 studies, 17 different methods were used to assess malnutrition. Four studies used multiple (ie, two to four) methods to assess malnutrition. Four studies used multiple criteria but integrated these together into one method to perform an assessment. In 53/69 (77\%) of the studies, BMI was used as single assessment method. Among these studies eight different cut-off points were used, 34/53 studies $(64 \%)$ used BMI $<18.5 \mathrm{~kg} / \mathrm{m}^{2}$. In seven studies, no cut-off values for BMI were described. Table 1 shows all the cut-off values of BMI used as single method.

\section{Capturing of the domains of malnutrition}

Table 2 presents the capturing of the domains of malnutrition per assessment method. ${ }^{34-91}$ Uptake or intake of nutrition (A) was addressed to some extent by four methods that were used in five of the 69 studies. Body composition (B) was addressed to some extent by all but two studies, 67/69 $(97 \%)$. Two methods did not address domain B, as these were methods that used self-reporting of diet quality and a food frequency questionnaire as assessment methods. Physical and/or cognitive functionality (C) was addressed to some extent by only $3 / 69$ studies $(4 \%)$.

Only 2 of the 17 different assessment methods that were used in the 69 studies captured all three domains of the definition, that is, the Subjective Global Assessment was used in two studies and the Mini Nutritional Assessment was used in one study. Forty-one studies (59\%) assessed malnutrition for the purpose of their primary aim. The three studies that used a method that captured all three domains of the definition, had a primary aim related to malnutrition.

Table 2 Comparison of 17 different assessment methods by malnutrition domain capturing

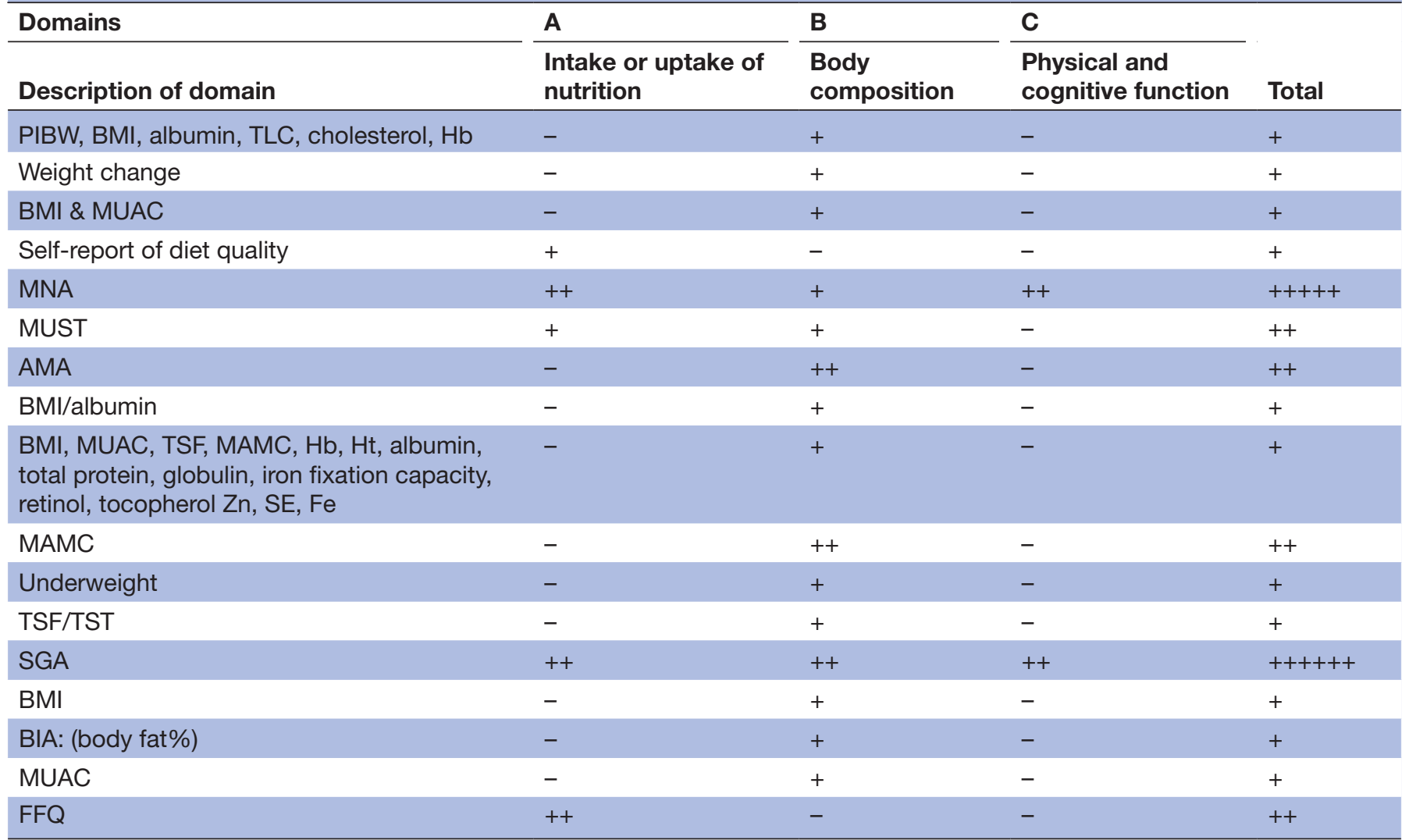

AMA, arm muscle area; BIA, bio-electrical impedance analysis; BMI, body mass index; Fe, iron; FFQ, Food Frequency Questionnaire; $\mathrm{Hb}$, haemoglobin; $\mathrm{Ht}$, haematocrit; MAMC, mid arm muscle circumference; MNA, mini nutritional assessment; MUAC, mid upper arm circumference; PIBW, percent ideal body weight; SE, selenium; SGA, subjective global assessment; TLC, total lymphocyte count; TSF, triceps skin fold ; TST, triceps skinfold thickness; Zn, zinc. 
Table 3 Subanalysis of malnutrition assessment methods

\begin{tabular}{|c|c|c|c|}
\hline $\begin{array}{l}\text { Year of } \\
\text { start data } \\
\text { collection }\end{array}$ & $\begin{array}{l}\text { No of } \\
\text { studies } \\
(n=69)\end{array}$ & $\begin{array}{l}\text { BMI as } \\
\text { the only } \\
\text { assessment } \\
\text { method } \\
\mathrm{N} \%\end{array}$ & $\begin{array}{l}\text { Use of an } \\
\text { assessment } \\
\text { method that } \\
\text { attributes to } \\
\text { three domains } \\
\%\end{array}$ \\
\hline 2000-2004 & 9 & 989 & - \\
\hline 2005-2009 & 12 & 758 & - \\
\hline 2010-2014 & 14 & 1393 & - \\
\hline 2015-2019 & 19 & 1579 & - \\
\hline $\begin{array}{l}\text { No available } \\
\text { data on } \\
\text { year of data } \\
\text { collection }\end{array}$ & 15 & 1067 & 320 \\
\hline Total & 69 & 5377 & 34 \\
\hline
\end{tabular}

A descriptive subanalysis, as shown in table 3, was performed to compare studies regarding their use of assessment tools, by their period of data collection. $^{3}{ }^{24-91}$ No differences were found between 5-year periods regarding the use of BMI as the only assessment method. The studies that used methods that capture all three domains of the ESPEN definition of malnutrition did not describe when their data was collected Of the 69 included studies, 18 studies (26\%) were on inpatients, 26 studies $(38 \%)$ on outpatients, $7(10 \%)$ on both type of patients and in 18 studies $(26 \%)$ the type of patients was not described.

\section{Risk of bias assessment}

Online supplemental material 2 shows the risk of bias assessment and details of the 69 included studies. ${ }^{324-91}$ Twenty-one of the 69 studies $(30 \%)$ did not describe the rationale for the assessment of malnutrition. Fifteen of the 69 studies $(22 \%)$ described their assessment method without clear cut-off values. Risk of bias was very low in 24 studies $(35 \%)$, low in 20 studies $(29 \%)$, medium in 20 studies $(29 \%)$ and high in five studies $(7 \%)$.

\section{DISCUSSION}

This review showed that most patients with $\mathrm{TB}$ are assessed for only one aspects of the construct of malnutrition. BMI is often used assessment method for malnutrition in studies with patients with $\mathrm{TB}$, even though it only partly covers just one malnutrition domain (domain B). In addition, while some studies did not report a cut-off value for BMI, in other studies different cut-off values for BMI were used, therefore making it difficult to compare these studies. The use of BMI could be justified from a public health perspective, since a low BMI is a characteristic of chronic malnutrition that involves loss of both fat and muscle tissue. ${ }^{15}$ However, the use of BMI alone for assessing malnutrition in this population is debatable. In clinical settings, disease-related malnutrition is the predominant type of malnutrition. Disease-related malnutrition is a (sub)acute condition, in which loss of weight and muscle/fat-free mass does not automatically result in a low BMI, while loss of weight and fatfree mass are related to poor clinical outcomes including increased morbidity and mortality. ${ }^{1592}$ With the current global overweight and obesity epidemic, patients with catabolic diseases such as TB may lose more than $20 \%$ of their weight and muscle mass within 3-6 months, and still show BMI values at or above normal range. ${ }^{93}$ When assessing malnutrition in patients with TB solely based on BMI, these patients will not be identified when they are malnourished, despite the therapeutic and prognostic implications of malnutrition. ${ }^{94}$

This review indicates that the international criteria for the assessment of malnutrition have not yet found their way into studies with patients with TB. The 2013 WHO guideline on nutritional care only refers to BMI as a method of assessing malnutrition for adults, which may contribute to the status quo. BMI is by far the most frequently used assessment method for malnutrition $(77 \%)$ in studies with patients with TB. Only a few $(4 \%)$ of the studies that reported on the assessment methods addressed all domains of the conceptual definition of malnutrition. For the studies performed after the ESPEN criteria of $2015^{95}$ and the GLIM criteria of $2018,{ }^{16}$ this may be explained by the fact that the WHO does not yet refer to these criteria in their communications. The GLIM criteria have been developed for global use and is therefore recommended to be used in any setting for all patients with TB. The GLIM framework does not include the domain of functionality as criterion.

There are some limitations in our study. First, our study focused on published articles and not on the underlying study protocol. In some cases, detailed information on the assessment and operationalisation of malnutrition might be available in the study protocol, however, it was not addressed in the article making it unavailable to the public domain. Second, implementation of new criteria in study protocols takes time. This implementation might take longer than the time period used in this review. Third: research and clinical practice are different settings and the results from our review are not a reflection of clinical practice. Nevertheless, we postulate that BMI is used the most commonly used method in clinical practice since the WHO recommends that BMI is the method to assess undernutrition/malnutrition.

Awareness of the presence of malnutrition and concept of malnutrition assessment in healthcare professionals working with patients with TB needs improvement. Future studies regarding malnutrition assessment in patients with TB should aim at implementation of international consensus criteria regarding malnutrition assessment. Using the same terminology for malnutrition may make a difference to our patients, improve outcomes as well as reduce chronic sequelae and help to end TB.

It should be stressed that we need to agree on using standardised methods for malnutrition assessment and 
interventions. However, malnutrition assessment should always be preceded by malnutrition screening with a validated tool (online supplemental material 3). ${ }^{16}$

In conclusion, most studies in adult patients with TB did not describe their assessment method for malnutrition. Most patients with TB are assessed for only one or two aspects of the conceptual definition of malnutrition. Various methods for assessing of malnutrition have been used, and only a very small proportion of the published studies on TB used an assessment method that fully reflects the definition of malnutrition. The use of international consensus criteria is recommended to establish systematic and uniform diagnostics and treatment of malnutrition.

\section{Author affiliations}

${ }^{1}$ Department of Pulmonary Diseases and Tuberculosis, University of Groningen, University Medical Center Groningen, Groningen, The Netherlands

${ }^{2}$ Tuberculosis Center Beatrixoord, University of Groningen, University Medical Center Groningen, Haren, The Netherlands

${ }^{3}$ Department of Health Sciences, Faculty of Science, Vrije Universiteit Amsterdam, and Amsterdam Public Health Research Institute, Amsterdam, The Netherlands ${ }^{4}$ Department of Clinical Pharmacy and Pharmacology, University of Groningen, University Medical Center Groningen, Groningen, The Netherlands

${ }^{5}$ Research Group Healthy Ageing, Allied Health Care and Nursing, Hanze University of Applied Sciences, Groningen, The Netherlands

${ }^{6}$ Department of Oral and Maxillofacial Surgery, University of Groningen, University

Medical Center Groningen, Groningen, The Netherlands

${ }^{7}$ Department of Infection, Barts Health NHS Trust, London, UK

${ }^{8}$ Blizard Institute, Queen Mary University of London, London, UK

${ }^{9}$ Department of Internal Medicine, University of Groningen, University Medical Center Groningen, Groningen, The Netherlands

${ }^{10}$ Faculty of Medicine and Health, University of Sydney, School of Pharmacy, Sydney, New South Wales, Australia

${ }^{11}$ Westmead Hospital, Sydney, New South Wales, Australia

${ }^{12}$ Marie Bashir Institute for Infectious Diseases and Biosecurity, University of Sydney, Sydney, Australia

Acknowledgements We thank Martine Sealy for her contribution to the conceptualisation and visualisation of this review.We thank Giovanni Sotgiu for his feedback on the manuscript. We thank the Central Medical Library of the University of Groningen for their help with designing our search strategy.

Contributors LtB: conception and design, data collection, acquisition, analysis, interpretation of data; drafting. MB: conception and design, data collection, acquisition, analysis, interpretation of data; revising draft critically for important intellectual content. HJ-W: interpretation of data and revising draft critically for important intellectual content. RB: acquisition, analysis, interpretation of data; drafting. MGGS: interpretation of data, and revising draft critically for important intellectual content. HAMK: interpretation of data, and revising draft critically for important intellectual content. WdL: interpretation of data, and revising draft critically for important intellectual content. ST: interpretation of data, and revising draft critically for important intellectual content. TSvdW: interpretation of data, and revising draft critically for important intellectual content. J-WCA: interpretation of data, and revising draft critically for important intellectual content. OWA: conception and design, interpretation of data; revising draft critically for important intellectual content. OWA is responsible for the overall content as guarantor.

Funding The authors have not declared a specific grant for this research from any funding agency in the public, commercial or not-for-profit sectors.

Competing interests HJ-W was codeveloper of the Patient-Generated Subjective Global Assessment@-based Pt-Global@ app/web tool.

Patient consent for publication Not applicable.

Ethics approval This study does not involve human participants.

Provenance and peer review Not commissioned; externally peer reviewed.

Data availability statement № data are available. No additional data available.
Supplemental material This content has been supplied by the author(s). It has not been vetted by BMJ Publishing Group Limited (BMJ) and may not have been peer-reviewed. Any opinions or recommendations discussed are solely those of the author(s) and are not endorsed by BMJ. BMJ disclaims all liability and responsibility arising from any reliance placed on the content. Where the content includes any translated material, BMJ does not warrant the accuracy and reliability of the translations (including but not limited to local regulations, clinical guidelines, terminology, drug names and drug dosages), and is not responsible for any error and/or omissions arising from translation and adaptation or otherwise.

Open access This is an open access article distributed in accordance with the Creative Commons Attribution Non Commercial (CC BY-NC 4.0) license, which permits others to distribute, remix, adapt, build upon this work non-commercially, and license their derivative works on different terms, provided the original work is properly cited, appropriate credit is given, any changes made indicated, and the use is non-commercial. See: http://creativecommons.org/licenses/by-nc/4.0/.

\section{ORCID iDs}

Lies ter Beek http://orcid.org/0000-0002-5058-920X

Tjip S van der Werf http://orcid.org/0000-0002-4824-1642

Onno W Akkerman http://orcid.org/0000-0001-5638-9260

\section{REFERENCES}

1 World Health Organisation. Global tuberculosis report. Geneva, 2020.

2 World Health Organization. Addressing poverty in TB control options for national TB control programmes. Geneva, 2005.

3 Bhargava A, Chatterjee M, Jain Y, et al. Nutritional status of adult patients with pulmonary tuberculosis in rural central India and its association with mortality. PLoS One 2013;8:e77979.

4 Nthiga I, David-Kigaru D, Mugendi J. The nutritional status of pulmonary tuberculosis patients aged 25-44 years attending tuberculosis clinic at Lodwar County and referral Hospital, Turkana County, Kenya 2017;2:2455-4898.

5 Wondmieneh A, Gedefaw G, Getie A, et al. Prevalence of undernutrition among adult tuberculosis patients in Ethiopia: $A$ systematic review and meta-analysis. J Clin Tuberc Other Mycobact Dis 2021;22:100211.

6 Zachariah R, Spielmann MP, Harries AD, et al. Moderate to severe malnutrition in patients with tuberculosis is a risk factor associated with early death. Trans R Soc Trop Med Hyg 2002;96:291-4.

7 Dodor E. Evaluation of nutritional status of new tuberculosis patients at the effia-nkwanta regional hospital. Ghana Med J 2008:42:22-8.

8 Subedi S, Mehta R, Parajuli P. Nutritional status of patients with pulmonary tuberculosis receiving anti-tuberculosis treatment at BP Koirala Institute of health sciences, Nepal 2019.

9 Bhargava A, Benedetti A, Oxlade O, et al. Undernutrition and the incidence of tuberculosis in India: national and subnational estimates of the population-attributable fraction related to undernutrition. Natl Med J India 2014;27:128-33.

10 Cederholm T, Barazzoni R, Austin P, et al. ESPEN guidelines on definitions and terminology of clinical nutrition. Clin Nutr 2017;36:49-64.

11 Sobotka L, Allison SP, Forbes A. Basics in clinical nutrition. Prague, Czech Republic: Publishing House Galen, 2011.

12 Dheda K, Barry CE, Maartens G. Tuberculosis. Lancet 2016;387:1211-26.

13 Choi R, Jeong BH, Koh WJ, et al. Recommendations for optimizing tuberculosis treatment: therapeutic drug monitoring, pharmacogenetics, and nutritional status considerations. Ann Lab Med 2017;37:97-107.

14 World Health Organization. The end TB strategy. Geneva, 2014.

15 Cederholm T, Bosaeus I, Barazzoni R. Diagnostic criteria for malnutrition - An ESPEN Consensus Statement. Clin Nutr 2015;34:335-40.

16 Cederholm T, Jensen GL, Correia MITD, et al. GLIM criteria for the diagnosis of malnutrition - A consensus report from the global clinical nutrition community. J Cachexia Sarcopenia Muscle 2019;10:207-17.

17 World Health Organisation. Nutritional care and support for patients with tuberculosis. Geneva, 2013.

18 Lacey K, Pritchett E. Nutrition care process and model: ADA adopts road map to quality care and outcomes management. J Am Diet Assoc 2003;103:1061-72.

19 Moher D, Liberati A, Tetzlaff J, et al. Preferred reporting items for systematic reviews and meta-analyses: the PRISMA statement. PLoS Med 2009;6:e1000097.

20 Turck D, Braegger CP, Colombo C, et al. ESPEN-ESPGHAN-ECFS guidelines on nutrition care for infants, children, and adults with cystic fibrosis. Clin Nutr 2016;35:557-77. 
21 Ouzzani M, Hammady H, Fedorowicz Z, et al. Rayyan-a web and mobile app for systematic reviews. Syst Rev 2016;5:210.

22 Ter Beek L, Vanhauwaert E, Slinde F, et al. Unsatisfactory knowledge and use of terminology regarding malnutrition, starvation, cachexia and sarcopenia among dietitians. Clin Nutr 2016;35:1450-6.

23 Sealy MJ, Nijholt W, Stuiver MM, et al. Content validity across methods of malnutrition assessment in patients with cancer is limited. J Clin Epidemiol 2016;76:125-36.

24 Mollah A, Shrivastava P, Das DK, et al. Nutritional status of adult tuberculosis patients in Burdwan municipality area of West Bengal. Indian J Community Health 2020;32:438-43.

25 White LV, Edwards T, Lee N, et al. Patterns and predictors of comorbidities in tuberculosis: a cross-sectional study in the Philippines. Sci Rep 2020:10:4100.

26 Edwards T, White LV, Lee N, et al. Effects of comorbidities on quality of life in Filipino people with tuberculosis. Int J Tuberc Lung Dis 2020;24:712-9.

27 Seid G, Ayele M. Undernutrition and mortality among adult tuberculosis patients in Addis Ababa, Ethiopia. Adv Prev Med 2020;2020:5238010.

28 Musuenge BB, Poda GG, Chen P-C. Nutritional status of patients with tuberculosis and associated factors in the health centre region of Burkina Faso. Nutrients 2020;12. doi:10.3390/nu12092540. [Epub ahead of print: 21 Aug 2020].

29 Ma'rufi I, Ali K, Jati SK, et al. Improvement of Nutritional Status among Tuberculosis Patients by Channa striata Supplementation: A True Experimental Study in Indonesia. Biomed Res Int 2020;2020:1-10.

30 White LV, Edwards T, Lee N. Co-morbidities in Filipino persons with tuberculosis: a cross-sectional study in urban and rural public TBDOTS facilities. Trans R Soc Trop Med Hyg 2019;113:S210

31 Wessels J, Walsh CM, Nel M. Smoking habits and alcohol use of patients with tuberculosis at Standerton tuberculosis specialised Hospital, Mpumalanga, South Africa. Health SA 2019;24:1146.

32 Wardani DWSR, Wahono EP. Predominant determinants of delayed tuberculosis sputum conversion in Indonesia. Indian J Community Med 2019;44:53-7.

33 Ren Z, Zhao F, Chen $\mathrm{H}$, et al. Nutritional intakes and associated factors among tuberculosis patients: a cross-sectional study in China. BMC Infect Dis 2019;19:907.

34 Rashak HA, Sánchez-Pérez HJ, Abdelbary BE, et al. Diabetes, undernutrition, migration and Indigenous communities: tuberculosis in Chiapas, Mexico. Epidemiol Infect 2019;147:e71

35 Mailu EW, Owiti P, Ade S, et al. Tuberculosis control activities in the private and public health sectors of Kenya from 2013 to 2017: how do they compare? Trans R Soc Trop Med Hyg 2019;113:740-8.

36 Lee N, White LV, Marin FP, et al. Mid-upper arm circumference predicts death in adult patients admitted to a TB ward in the Philippines: a prospective cohort study. PLoS One 2019;14:e0218193.

37 Hussien B, Hussen MM, Seid A, et al. Nutritional deficiency and associated factors among new pulmonary tuberculosis patients of bale zone hospitals, Southeast Ethiopia. BMC Res Notes 2019;12:751.

38 Hoyt KJ, Sarkar S, White L, et al. Effect of malnutrition on radiographic findings and mycobacterial burden in pulmonary tuberculosis. PLoS One 2019;14:e0214011.

39 Gashaw F, Bekele S, Mekonnen Y, et al. High helminthic co-infection in tuberculosis patients with undernutritional status in northeastern Ethiopia. Infect Dis Poverty 2019;8:88.

40 Feleke BE, Feleke TE, Biadglegne F. Nutritional status of tuberculosis patients, a comparative cross-sectional study. BMC Pulm Med 2019;19:182.

41 da Silva LF, Skupien EC, Lazzari TK, et al. Advanced glycation end products (age) and receptor for age (RAGE) in patients with active tuberculosis, and their relationship between food intake and nutritional status. PLoS One 2019;14:e0213991.

42 Chebrolu P, Laux T, Chowdhury S, et al. The risk of refeeding syndrome among severely malnourished tuberculosis patients in Chhattisgarh, India. Indian J Tuberc 2020;67:152-8.

43 Benzekri NA, Sambou JF, Tamba IT, et al. Nutrition support for HIVTB co-infected adults in Senegal, West Africa: a randomized pilot implementation study. PLoS One 2019;14:e0219118.

44 Abdullahi OA, Ngari MM, Sanga D, et al. Mortality during treatment for tuberculosis; a review of surveillance data in a rural County in Kenya. PLoS One 2019;14:e0219191.

45 Skupien EC, Lazzari TK, Coutinho SE, et al. The relation between leptin and inflammatory markers with respiratory and peripheral muscle strength in tuberculosis: a case-control study. Clin Respir J 2018;12:2559-65.
46 Cheng W, Zhang S, Li Y, et al. Intestinal tuberculosis: clinicopathological profile and the importance of a high degree of suspicion. Trop Med Int Health 2019;24:81-90.

47 Lazzari TK, Forte GC, Silva DR. Nutrition status among HIV-positive and HIV-negative inpatients with pulmonary tuberculosis. Nutr Clin Pract 2018;33:858-64.

48 Sattler FR, Chelliah D, Wu X, et al. Biomarkers Associated with Death After Initiating Treatment for Tuberculosis and HIV in Patients with Very Low CD Cells. Pathog Immun 2018;3:46-62.

49 Rao VG, Bhat J, Yadav R, et al. A comparative study of the socioeconomic risk factors for pulmonary tuberculosis in the Saharia tribe of Madhya Pradesh, India. Trans R Soc Trop Med Hyg 2018;112:272-8.

50 Pande T, Huddart S, Xavier W, et al. Prevalence of diabetes mellitus amongst hospitalized tuberculosis patients at an Indian tertiary care center: a descriptive analysis. PLoS One 2018;13:e0200838.

51 Gurung LM, Bhatt LD, Karmacharya I, et al. Dietary practice and nutritional status of tuberculosis patients in Pokhara: a cross sectional study. Front Nutr 2018;5:1-6.

52 Piparva KG, Jansari G, Singh AP. Evaluation of treatment outcome and adverse drug reaction of directly observed treatment (DOT) plus regimen in multidrug-resistant tuberculosis (MDR-TB) patients at district tuberculosis centre Rajkot. Perspect Clin Res 2018;9:165-9.

53 Hochberg NS, Sarkar S, Horsburgh CR, et al. Comorbidities in pulmonary tuberculosis cases in Puducherry and Tamil Nadu, India: opportunities for intervention. PLoS One 2017;12:e0183195.

54 Bhat J, Rao VG, Sharma RK, et al. Investigation of the risk factors for pulmonary tuberculosis: A case-control study among Saharia tribe in Gwalior district, Madhya Pradesh, India. Indian J Med Res 2017:146:97-104.

55 Abdelbary BE, Garcia-Viveros M, Ramirez-Oropesa H, et al. Predicting treatment failure, death and drug resistance using a computed risk score among newly diagnosed TB patients in Tamaulipas, Mexico. Epidemiol Infect 2017;145:3020-34.

56 Pandit A, Kumar Pandey A, Department of Medicine, Index Medical College, Indore, M.P., India. Liver dysfunction in pulmonary tuberculosis patients on dots: a study and review. J Gastroenterol Hepatol Res 2016:5:2254-60.

57 Buntoro IF, Kristin E S. Decrease of liver function after treatment of antituberculosis drugs in tuberculosis patients with malnutrition and alcohol consumption. Int J Pharm Pharm Sci 2016;8:269-73.

58 Araújo-Mariz C, Lopes EP, Acioli-Santos B, et al. Hepatotoxicity during treatment for tuberculosis in people living with HIV/AIDS PLoS One 2016;11:e0157725.

59 Gebrecherkos T, Gelaw B, Tessema B. Smear positive pulmonary tuberculosis and HIV co-infection in prison settings of North Gondar zone, Northwest Ethiopia. BMC Public Health 2016;16:1091.

60 McLachlan I, Visser WI, Jordaan HF. Skin conditions in a South African tuberculosis Hospital: prevalence, description, and possible associations. Int J Dermatol 2016;55:1234-41.

61 Ezeamama AE, Mupere E, Oloya J, et al. Age, sex, and nutritional status modify the CD4+ T-cell recovery rate in HIV-tuberculosis coinfected patients on combination antiretroviral therapy. Int $J$ Infect Dis 2015;35:73-9.

62 Medellín-Garibay SE, Cortez-Espinosa N, Milán-Segovia RC, et al. Clinical pharmacokinetics of rifampin in patients with tuberculosis and type 2 diabetes mellitus: association with biochemical and immunological parameters. Antimicrob Agents Chemother 2015;59:7707-14.

63 Te Brake LH, Ruslami R, Later-Nijland H. Exposure to total and protein-unbound rifampicin is not affected by malnutrition in Indonesian tuberculosis patients. Antimicrob Agents Chemother 2015;74:986-90.

64 Golemba AS, Ferreyra FGE, Martearena RE, et al. Drug-induced hepatotoxicity and tuberculosis in a hospital from the Argentinian northeast: cross-sectional study. Medwave 2015;15:e6135.

65 Bacelo AC, Ramalho A, Brasil PE, et al. Nutritional supplementation is a necessary complement to dietary counseling among tuberculosis and Tuberculosis-HIV patients. PLoS One 2015;10:e0134785

66 Kumar NSS, Hemraj SK, Dutt RA. Phase angle measurement in pulmonary tuberculosis patients and control subjects using bioimpedance analysis. Indian J Tuberc 2014:61:224-31.

67 Tian P-W, Wang Y, Shen Y-C, et al. Different risk factors of recurrent pulmonary tuberculosis between Tibetan and Han populations in Southwest China. Eur Rev Med Pharmacol Sci 2014:18:1482-6.

68 Oliveira MG, Delogo KN, Oliveira HMdeMGde, et al. Anemia in hospitalized patients with pulmonary tuberculosis. J Bras Pneumol 2014:40:403-10

69 Maeda S, Hang NTL, Lien LT, et al. Mycobacterium tuberculosis strains spreading in Hanoi, Vietnam: Beijing sublineages, genotypes, 
drug susceptibility patterns, and host factors. Tuberculosis 2014;94:649-56.

70 Miyata S, Tanaka M, Ihaku D. The prognostic significance of nutritional status using malnutrition universal screening tool in patients with pulmonary tuberculosis. Nutr $J$ 2013;12:42.

71 R I, Bambang W, Priatna DY. The effect of zinc, lysine and vitamin A supplementation to increase cellular immune response of pulmonary tuberculosis patients. J Trace Elem Med Biol 2013;27:21.

72 Bakari M, Wamsele J, MacKenzie T, et al. Nutritional status of HIVinfected women with tuberculosis in Dar es Salaam, Tanzania. Public Health Action 2013;3:224-9.

73 Miyata S, Tanaka M, Ihaku D. Full mini nutritional assessment and prognosis in elderly patients with pulmonary tuberculosis. J Am Coll Nutr 2013;32:307-11.

74 Chittoor G, Arya R, Farook VS, et al. Epidemiologic investigation of tuberculosis in a Mexican population from Chihuahua state, Mexico: a pilot study. Tuberculosis 2013;93(Suppl):S71-7.

75 Islam QS, Ahmed SM, Islam MA, et al. Beyond drugs: tuberculosis patients in Bangladesh need nutritional support during convalescence. Public Health Action 2013:3:136-40.

76 Piva SGN, Costa MdaCN, Barreto FR, et al. Prevalence of nutritional deficiency in patients with pulmonary tuberculosis. J Bras Pneumol 2013:39:476-83.

77 Mupere E, Malone L, Zalwango S, et al. Lean tissue mass wasting is associated with increased risk of mortality among women with pulmonary tuberculosis in urban Uganda. Ann Epidemiol 2012;22:466-73.

78 Miyata S, Tanaka M, Ihaku D. Subjective global assessment in patients with pulmonary tuberculosis. Nutr Clin Pract 2011;26:55-60.

79 Kawai K, Villamor E, Mugusi FM, et al. Predictors of change in nutritional and hemoglobin status among adults treated for tuberculosis in Tanzania. Int $J$ Tuberc Lung Dis 2011;15:1380-9.

80 de Jong BC, Adetifa I, Walther B, et al. Differences between tuberculosis cases infected with Mycobacterium africanum, West African type 2, relative to Euro-American Mycobacterium tuberculosis: an update. FEMS Immunol Med Microbiol 2010;58:102-5.

81 Podewils LJ, Holtz T, Riekstina V, et al. Impact of malnutrition on clinical presentation, clinical course, and mortality in MDR-TB patients. Epidemiol Infect 2011;139:113-20.

82 Warmelink I, van Altena R, ten Hacken N, et al. Nutritional status and vitamin D3 during antimicrobial treatment. Lancet 2011;377:1407-8.
83 Mupere E, Zalwango S, Chiunda A, et al. Body composition among HIV-seropositive and HIV-seronegative adult patients with pulmonary tuberculosis in Uganda. Ann Epidemiol 2010;20:210-6.

84 Singla R, Sharma SK, Mohan A, et al. Evaluation of risk factors for antituberculosis treatment induced hepatotoxicity. Indian J Med Res 2010;132:81-6.

85 Gambhir HS, Kaushik RM, Kaushik R, et al. Tobacco smokingassociated risk for tuberculosis: a case-control study. Int Health 2010;2:216-22.

86 Pakasi TA, Karyadi E, Suratih NMD, et al. Zinc and vitamin A supplementation fails to reduce sputum conversion time in severely malnourished pulmonary tuberculosis patients in Indonesia. Nutr J 2010;9:41.

87 Khoharo HK, Ansari S, Siddiqui AA. Standard antituberculosis drug induced hepatotoxicity: do the risk factors matter? J Liaquat Uni Med Health Sci 2010;9:84-7.

$88 \mathrm{Kim}$ J-S, Wilson JM, Lee S-R. Dietary implications on mechanisms of sarcopenia: roles of protein, amino acids and antioxidants. J Nutr Biochem 2010;21:1-13.

89 Ulasli SS, Ulubay G, Arslan NG, et al. Characteristics and outcomes of end-stage renal disease patients with active tuberculosis followed in intensive care units. Saudi J Kidney Dis Transpl 2009;20:254-9.

90 Pakasi TA, Karyadi E, Dolmans WMV, et al. Malnutrition and sociodemographic factors associated with pulmonary tuberculosis in Timor and Rote Islands, Indonesia. Int J Tuberc Lung Dis 2009;13:755-9.

91 Martins N, Morris P, Kelly PM. Food incentives to improve completion of tuberculosis treatment: randomised controlled trial in Dili, TimorLeste. BMJ 2009;339:b4248.

92 Correia MITD, Waitzberg DL. The impact of malnutrition on morbidity, mortality, length of hospital stay and costs evaluated through a multivariate model analysis. Clin Nutr 2003;22:235-9.

93 Gonzalez MC, Correia MITD, Heymsfield SB. A requiem for BMI in the clinical setting. Curr Opin Clin Nutr Metab Care 2017;20:314-21.

94 Jensen GL, Mirtallo J, Compher C, et al. Adult starvation and disease-related malnutrition: a proposal for etiology-based diagnosis in the clinical practice setting from the International consensus guideline Committee. JPEN J Parenter Enteral Nutr 2010;34:156-9.

95 Cederholm T, Bosaeus I, Barazzoni R, et al. Diagnostic criteria for malnutrition - An ESPEN Consensus Statement. Clin Nutr 2015;34:335-40. 